\section{Psychosocial risk factors at the workplace: is there enough evidence to establish reference values?}

\section{F G Benavides, J Benach, C Muntaner}

\section{Job control and its effect on public health}

l: $\mathrm{n}$ the past two decades, research on workplace psychosocial risk factors has produced a large body of theoretical and empirical research. ${ }^{1}$ An extensive range of health end points, especially cardiovascular diseases, ${ }^{2}$ have been associated with the psychosocial work environment. Two main job stress models: the demand-control-social support ${ }^{34}$ and the effort-reward imbalance ${ }^{5}$ are being widely used in occupational health research, although a significant and valuable theoretical and methodological amount of criticism has also been raised.$^{67}$ Both models try to explain the effects of workplace psychosocial risk factors on health in terms of the interaction among their different dimensions, as well as independently from each other: mainly job control and job demands in the first, and intrinsic and extrinsic efforts and reward in the last. Conceptual and empirical overlap between both models has been remarkable and a call for a unified model has been suggested. ${ }^{8}$ One important distinction is that the demand-control model attempts to capture features of work organisation while the effort-reward imbalance model attempts to capture work organisation consequences on the worker. Both models, however, use worker self reports as the main method of assessment.

Work pace control, autonomy, learning new skills, or participation in company decision making are specific psychosocial risk factors included into the job control dimensions. Workload, work pace, and conflicting demands are specific risk factors from job demand dimension. The catalogue of specific psychosocial risk factors may provisionally be completed with factors such as promotion prospects and job insecurity from the efforts-rewards imbalance model. However, as in the case of the history of Mendeleev's periodic table, the catalogue of risk factors seems far from being finished and an ongoing assessment of the independent effects and the interactions of each of those specific occupational psychosocial risk factors on health is needed. Furthermore, to better understand the whole process for which psychosocial risk factors produce ill health it is also necessary to take into account living conditions outside the workplace when working life is analysed. We find an example of those two crucial points in work organisation research in the current issue of the journal where Ala-Mursula et al find an independent effect of a specific psychosocial risk factor: working time control, on self rated health and sickness absence." According to the authors, and following a rich tradition of gender, homework, and workplace stressors ${ }^{10}$ poor working time control has an independent effect on health in women but not in men. Gender differences in roles at home might be an explanation of those results.

Research that takes organisational approaches into account will be essential to help to make effective prevention activities to improve the psychosocial work environment. ${ }^{11}{ }^{12}$ Moreover, current evidence justifies a deep discussion to establish reference values to facilitate decisions in the occupational risk evaluation process, such as often happens with physical or chemical risk factors. ${ }^{13}$

Whereas concerns have been raised in the case of occupational standards exposure limits, ${ }^{14}$ the particular nature of psychosocial risk factors brings even more difficulties to reach reference values. One of these limitations, perhaps the most relevant, is the difficulty to measure psychosocial work environment by an external characteristic of work, ${ }^{15}$ independently of self rated perception. We need to keep in mind that features of psychosocial work environment are structural rather than individual. However, measurement of psychosocial risk factors is usually done by questionnaires referred to processes that are not directly observed by investigators but referred by the workers themselves. This fact may introduce a great variability in the estimates because psychosocial risk factors are measured on the base of attitudes. ${ }^{16}$ But variability is not synonymous of subjectivity because, as Kristensen has pointed out, ${ }^{17}$ psychosocial factors can also be estimated by objective methods regardless of the researcher and according to explicit and prior rules. For example, self reports of psychosocial work environment tend to yield high correlations with observer ratings of the same occupations ${ }^{18}$ and confirmatory factor analyses of these scales, taking into account methods variance, tend to produce the predicted demands-control factorial structure. ${ }^{19}$ Indeed, as it has been suggested by Kasl, ${ }^{20}$ measures of perceived psychosocial risk factors could have an analogous significance to measure a biomarker of exposure. Average methods, in which all workers in a given job will have the score of this job, can be a way to estimate a proxy of the environmental doses of a psychosocial risk factor. Schwartz et $a l^{21}$ and later Johnson and Stewart ${ }^{22}$ have shown how imputation of occupation specific psychosocial work environment scores can be used as proxies for directly observed exposures. On this basis, it is possible to obtain average scores by job in national or areabased representative surveys, ${ }^{23}$ and use them as reference values to guide preventive activities at workplace. ${ }^{24}$

The task to set up reference values useful to decision makers is not easy. Changing work environments across time and place plus heterogeneity of psychosocial work environments within occupations make this an elusive goal. In fact, it has not been easy for chemical and physical risk factors, ${ }^{25} 26$ and certainly it will not be for psychosocial risk factors. We will need much more information, for instance, about patterns of exposure. But this is the way to go if we want to use the knowledge that we already have into practical prevention inside our workplaces.

$J$ Epidemiol Community Health 2002;56:244-245

\section{Authors' affiliations}

F G Benavides, J Benach, Occupational Health Research Unit, Department of Health and Experimental Sciences, Universitat Pompeu Fabra, Barcelona, Spain

C Muntaner, Department of Psychiatric and Community Health, University of Maryland, Baltimore, USA

Correspondence to: Professor F G Benavides, Occupational Health Research Unit, Department of Health and Experimental Sciences, Universitat Pompeu Fabra, C/Dr Aiguader 80, 08003 Barcelona, Spain;

fernando.benavides@cexs.upf.es

\section{REFERENCES}

1 Theorell T. Working conditions and health. In: Berkman L, Kawachi I, eds. Social epidemiology. Oxford: Oxford University Press, 2000.

2 Schnall P, Belkic K, Landsbergis P, et al, eds The workplace and cardiovascular disease. Philadelphia: Hanley and Belfus, 2000.

3 Karasek R, Theorell T. Healthy work. New York: Basic Books, 1990.

4 Johnson JV, Hall EM. Job strain, workplace social support and cardiovascular disease: a cross-sectional study of a random sample of 
the Swedish working population. Am J Public Health 1988:78:1336-42.

5 Siegrist J. Adverse health effects of high-effort/low-reward conditions. Journal of Occupational Health Psychology

1996:1:27-41.

6 Kristensen T. The demand-control-support model: methodological challenges for future research. Stress Medicine 1995;11:17-26.

7 Muntaner C, O'Campo PJ. A critical appraisal of the demand/control model of the psychosocial work environment: epistemological, social, behavioral and class considerations. Soc Sci Med

1993:36:1509-17.

8 Bosma H, Peter R, Siegrist J, et al. Two alternative job stress models and the risk of coronary heart disease. Am J Public Health 1998;88:68-74

9 Ala-Mursula L, Vahtera J, Kivimäki $M$, et al. Employee control over working times: associations with subjective health and sickness absences. J Epidemiol Community Health 2002;56:272-8.

10 Barnett RC, Davidson H, Marshal NL. Physical symptoms and the interplay of work and family roles. Health Psychology 1991;10:94-101.

11 Campbell J, Muphy LR, Hurrell JJ, eds. Stress and well-being at work. Washington DC: American Psychological Association, 1997.

12 Kristensen T, Kornitzer M, Alfredsson L. Social factors, work, stress and cardiovascular disease prevention in the European Union. Brussels: European Heart Network, 1998.

13 Annual Reports of the Committees on Threshold Limit Values (TLVs) and Biological Exposure Indices (BEls). http:// www.acgih.org/Products/tlvintro.htm

14 Ove Hansson S. Setting the limit. Occupational health standards and the limits of science. New York: Oxford University Press, 1998

15 Stansfeld SA, North FM, White I, et al. Work characteristics and psychiatric disorder in civil servants in London. J Epidemiol Community Health 1995:49:48-53.

16 Greiner BA, Ragland DR, Krause N, et al. Objective measurement of occupational stress factors -an example with San Francisco urban transit operators. Journal of Occupational Health Psychology 1997;2:325-42.

17 Kristensen TS. Job stress and cardiovascular disease: a theoretic critical review. Journal of Occupational Health Psychology 1996; 1:246-60.

18 Muntaner C, Eaton WW, Garrison R. Dimensions of the psychosocial work environment in a sample of the US metropolitan population. Work and Stress 1993;7:351-63.

19 Muntaner C, Schoenbach C. Psychosocial dimensions of work in US metropolitan areas: a test of the Demand/Control and
demand/Control/Support models. Int J Health Services 1994;24:337-53.

20 Kasl SV. Measuring job stressors and studying the health impact of the work environment: an epidemiologic commentary. Journal of Occupational Health Psychology 1998;3:390-401.

21 Schwartz JE, Pieper CF, Karasek RA. A procedure for linking psychosocial job characteristics data to health surveys. Am J Public Health 1988;78:904-9.

22 Johnson JV, Stewart WF. Measuring work organization exposure over the life course with a job-exposure matrix. Scand J Work Environ Health 1993;19:21-8.

23 Muntaner C, Tien A, Eaton WW, et al. Occupational characteristics and the occurrence of psychotic disorders. Soc Psychiatry Psychiatr Epidemiol 1991;26:273-80.

24 Van der Klink JJL, Blonk RWB, Scheme AH, et al. The benefits of interventions for work-related stress Am J Public Health 2001;91:270-6.

25 KauppinenT. Exposure assessment -a challenge for occupational epidemiology? Scand J Work Environ Health 1996;22:401-2.

26 Pearce N, Sanjose S, Boffeta $\mathrm{P}$, et al. Limitations of biomarkers of exposure in cancer epidemiology. Epidemiology 1995;6:190-4.

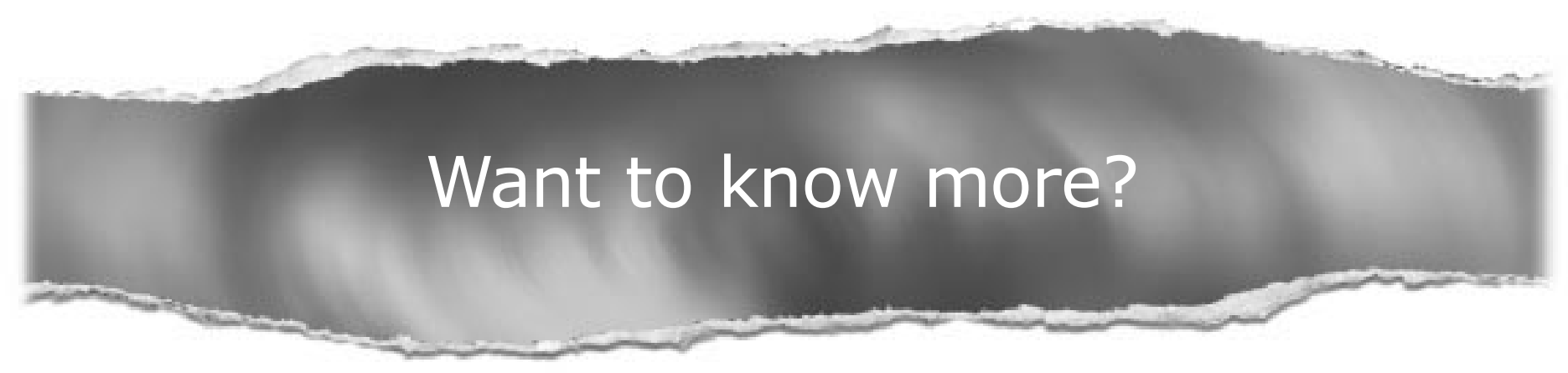

Data supplements

Limited space in printed journals means that interesting data and other material are often edited out of articles; however, limitless cyberspace means that we can include this information online.

Look out for additional tables, references, illustrations.

www.jech.com 